\title{
A Voz do Campo: uma Experiência unindo Educação e Tecnologia no Meio Rural
}

\author{
Firmiano A. R. Silva ${ }^{1}$, Walteno M. Parreira Júnior ${ }^{2}$, Carlos A. G. Pavan ${ }^{1}$ \\ ${ }^{1}$ Instituto Federal do Triângulo Mineiro (IFTM) - Campina Verde-MG, \\ ${ }^{2}$ Instituto Federal do Triângulo Mineiro (IFTM) - Uberlândia Centro. \\ firmianodiftm.edu.br, waltenomartinseiftm.edu.br, \\ carlospavaneiftm.edu.br
}

\begin{abstract}
Resumo. Esse trabalho relata o projeto de extensão "Aprender e Ensinar"do IFTM - Campina Verde. O objetivo inicial do projeto era colaborar com a redução da exclusão digital no meio rural, oferecendo um curso básico de Informática a alunos de uma escola na zona rural com a participação de alunos do Curso Técnico em Informática do IFTM. No decorrer do curso, as necessidades observadas levaram a uma mudança na metodologia, que passou a seguir um modelo diferente dos convencionais; orientado ao protagonismo dos alunos, baseado nos conceitos da educação tecnológica e educomunicação, o curso culminou com a produção coletiva de um vídeo com apoio das Tecnologias da Informação e Comunicação (TIC's).
\end{abstract}

\begin{abstract}
This paper shows the results of project "Learning and Teaching" of IFTM - Campina Verde. The main target of the project was to collaborate with the reduction of the digital divide in rural areas, offering a basic course in Computer Programming for students from a school in the country side with the participation of students of the Technical Course in Computer Programming from IFTM. During the course observed needs led to a change in methodology which now follows a different model from the conventional; oriented to the role of students and with an approach based in the concepts of technology education and educational communication, the course culminated with the production of a video as a way to express the support of ICT.
\end{abstract}

\section{Introdução}

O campo da educação é um palco permanente de controvérsias. Muito se discute sobre a necessidade de cada contexto, bem como os rumos que devemos seguir na busca por uma educação de qualidade.

Apesar de muito se discutir as políticas públicas e práticas pedagógicas, essas continuam a seguir um modelo que se mostram recorrentes em toda a nossa história: as 
V Congresso Brasileiro de Informática na Educação (CBIE 2016)

Anais dos Workshops do V Congresso Brasileiro de Informática na Educação (CBIE 2016)

ideias continuam sem sair do papel, fazendo-se urgente o alinhamento entre as discussões acadêmicas e o espaço escolar.

Por meio dos noticiários das mídias, podemos evidenciar a falta de estruturação socioeconômica e da educação básica das comunidades rurais, principalmente quando comparado às áreas urbanas. Esse analfabetismo digital não se restringe aos recursos tecnológicos, midiáticos e de conectividade oferecidos pelas escolas em seus laboratórios de Informática; mas também pelo fraco estímulo intelectual e poucas condições de expressividade no processo de formação. O resultado é umdesnivelamento dessas crianças e jovens em relação ao conhecimento e utilização das mídias digitais. Tal fato pode igualmente causar transtornos e/ou prejuízos também em relação ao mercado de trabalho, colocando-o em desvantagem na hora de concorrer a uma vaga.

É nesta lacuna que se insere o nosso projeto: não apenas na minimização da exclusão digital no meio rural, mas também na "alfabetização digital" [MARTIN, 2014], o que estimula os alunos a buscar novas formas de comunicação e expressão, tornando-os mais seguros de si nos processos que envolvem o seu aprendizado.

A próxima seção é destinada a compor o nosso arcabouço teórico que subsidiou ações e reflexões no decorrer do projeto.

\section{Arrumando as malas: referencial teórico}

É forçoso reconhecer esforços presentes no ideário de programas e políticas públicas como o ECA (Estatuto da Criança e do Adolescente), o PNE (Plano Nacional de Educação), e a LDB, Lei 9394/96, que estabelece as Diretrizes e Bases da Educação Nacional, a qual determina em seu Artigo 28, que

Art.28. Na oferta de educação básica para a população rural, os sistemas de ensino promoverão as adaptações necessárias à sua adequação às pecualiaridades da vida rural e de cada região, especialmente:

I - conteúdos curriculares e metodologias apropriadas às reais necessidades e interesses dos alunos da zona rural;

II - organização escolar própria, incluindo adequação do calendário escolar às fases do ciclo agrícola e às condições climáticas;

III - adequação à natureza do trabalho na zona rural [BRASIL, 1996, p.12, grifo nosso]. 
V Congresso Brasileiro de Informática na Educação (CBIE 2016)

Anais dos Workshops do V Congresso Brasileiro de Informática na Educação (CBIE 2016)

Não é segredo para ninguém que de longa data as atividades rurais estão sendoimpactadas pelas tecnologias, o que torna a educação tecnológica uma necessidade primária para os alunos da zona rural.

De acordo com o Censo Escolar 2014 [CENSO], apenas 14\% das escolas rurais possuem acesso à internet. Esse quadro de exclusão é ainda mais acentuado em relação às mídias digitais.

A inserção social dessas crianças e jovens em conhecimentos básicos de informática e uso da rede de informação permite que o aluno adquira habilidades e atitudes necessárias para comunicar-se e desenvolver sua autonomia, reduzindo o impacto da situação acima descrita nessas comunidades.

Segundo Almeida (2005, p. 71), estar na sociedade da informação não é apenas ter acesso às TICs, mas saber usá-la para buscar e selecionar informações que permitam resolver os "problemas do cotidiano, compreender o mundo e atuar na transformação de seu contexto".

A educação tecnológica no seu sentido mais amplo significa saber usar a tecnologia ou, como nos diz Sodré (2012, p. 174), é usar a tecnologia de dentro para fora. "Não é, assim, o simples ser moderno do objeto que lhe agrega valor social, mas sua inserção numa trama de relações intersubjetivas capaz de dar-lhe um curso transformador". Tal fato também é evidenciado por Almeida (2005), ao afirmar que

O uso da TIC com vistas à criação de uma rede de conhecimentos favorece a democratização do acesso à informação, a troca de informações e experiências, a compreensão crítica da realidade e o desenvolvimento humano, social, cultural e educacional. [ALMEIDA, 2005, p. 71]

E baseado nessas ideias que surgiu o projeto de extensão "Aprender e Ensinar" regulamentado pelo edital no 01/2015 do Programa de Apoio a Projetos de Extensão do Instituto Federal de Educação, Ciência e Tecnologia do Triângulo Mineiro - campus Avançado Campina Verde, idealizado inicialmente com intuito de colaborar com a redução da exclusão digital no meio rural, oferecendo um curso básico de Informática aos alunos do ensino fundamental da Escola Estadual Serra da Moeda localizada na zona rural do município de Itapagipe/MG, limítrofe de Campina Verde.

O projeto contou com a participação dos alunos do Curso Técnico em Informática do IFTM, que ministraram as aulas supervisionados pelo orientador do projeto. 
V Congresso Brasileiro de Informática na Educação (CBIE 2016)

Anais dos Workshops do V Congresso Brasileiro de Informática na Educação (CBIE 2016)

No decorrer do curso percebeu-se o desnivelamento das crianças em relação ao conhecimento e utilização das mídias digitais; e, que tal desigualdade não se resume apenas ao acesso ou não a laboratórios, de informática ou espaços multimídia, apesar destes ficarem na maior parte do tempo inacessíveis aos alunos, mas também pelo pequeno estímulo intelectual e poucas condições de expressividade no processo de formação.

Tal realidade provocou sensivelmente o autor do projeto que buscou formas de amenizar o problema o que fez por emergir durante as atividades ações e práticas pedagógicas educomunicativas resultando num ambiente acolhedor e propenso ao desenvolvimento do protagonismo comunicativo dos alunos. O desafio então passou a ser integrar o mundo formal e o cotidiano dos jovens da comunidade num processo de aprendizado não apenas tecnológico mas também de comunicação. As aulas então foram revistas e passaram a seguir uma prática pedagógica educomunicativa tendo como meta prioritária o reconhecimento do protagonismo, conforme descreve Soares (2011), e por abordagens baseadas do contexto sócio-cultural, político, econômico e pedagógico [APARICI, 2014].

A partir dessa perspectiva o curso assumiu os princípios da educomunicação que, de acordo com Soares (2002), se caracteriza por um conjunto de ações cuja finalidade é integrar às práticas educativas os processos comunicativos, baseadas no diálogo e na participação; princípios esses também oriundos da comunicação dialógica defendida por Freire (2000).

E complementando o contexto, escreve Coutinho (2005, p. 19) que "talvez o grande desafio para a educação na sociedade telemidiática seja justamente o de estimular a expressão dessa complementaridade que permanece, muitas vezes, latente entre a educação e as mídias [...]".

$\mathrm{O}$ produto final do projeto foi a produção de um vídeo, que contou com a participação de todos os alunos da escola. No vídeo os alunos puderam externar de forma crítica seus anseios e dificuldades. Ao participarem desse processo de “alfabetização digital” ratificado por Martín (2014, p. 192), como “a alfabetização necessária para o século XXI", essas crianças e jovens foram atendidos em uma necessidade educativa, vivenciando a liberdade de manusear equipamentos eletrônicos de propósito geral como câmeras digitais, unidades de armazenamento e tablets; e, 
V Congresso Brasileiro de Informática na Educação (CBIE 2016)

Anais dos Workshops do V Congresso Brasileiro de Informática na Educação (CBIE 2016)

produzir material digital de suas atividades como fotos, vídeos e textos, desenvolvendo sua individualidade e criatividade, assumindo assim o papel de protagonistas na transformação da própria realidade. Afinal, como postula Rosa (1994, p.16), “toda mudança nasce [apenas] do casamento entre a necessidade e o desejo".

\section{A jornada: metodologia, objetivo(s) e discussão.}

Os participantes do projeto cursavam do sexto ao nono ano do ensino básico em turmas multisseriadas, situação comum em escolas rurais. Por questões de espaço físico, os participantes foram divididos em dois grupos: um com os do sexto e sétimo anos e outro com os do oitavo e nono anos. As aulas com duração de duas horas cada ocorreram semanalmente às quartas-feiras num total de 14 encontros.

O curso foi modelado para oferecer uma formação básica sobre fundamentos de informática. O material didático essencialmente na forma digital foi formatado pelos alunos do IFTM utilizando aplicativos como Socrative, Prezi e Edlin. Esse modelo precisou ser adaptado.Para dar voz aos participantes, foi sugerido a eles que documentassem as atividades das aulas de acordo com o seu olhar manuseando equipamentos como câmeras fotográficas, filmadoras e tablets. Esse empoderamento causado pela liberdade do uso das ferramentas, bem como a confiança nas relações entre os protagonistas do processo, fez com que aos poucos eles participassem mais das atividades e, rompendo o silêncio, demonstraram comportamentos de autonomia deixando a posição de meros receptores de informação.

Tal fato, evidenciou o curso dentro de paradigmas educacionais centrado no aluno e ainda com uma abordagem educomunicativa. Seguindo esse modelo, as aulas passaram a ser planejadas de forma ágil e dinâmica sempre com a intenção de expressar ou transmitir algo partindo de uma necessidade cotidiana dos alunos, pois, "só pensamos sobre alguma coisa quando esta nos parece intrigante, curiosa ou interessante" [ROSA, 1994, p. 48]. Assim, o objetivo, conteúdo ou destinatários escolhidos é que definiam que tecnologias ou dispositivosseriam usados no memento.

Paralelamente, eram inseridos os conceitos para utilização das ferramentas tecnológicas necessárias, como computador, câmeras fotográficas, filmadora, e aplicativos de edição e navegação. 
V Congresso Brasileiro de Informática na Educação (CBIE 2016)

Anais dos Workshops do V Congresso Brasileiro de Informática na Educação (CBIE 2016)

Na conclusão do curso foi promovidoa elaboração coletiva de um produto digital com a intensão de estimular nos alunos o desenvolvimento da capacidade de se comunicar utilizando recursos de informação e comunicação. Os alunos opinaram sobre uma mídia a ser utilizada podendo ser uma cartilha, blog, jornal ou vídeo. A opção dos alunos foi fazer um vídeo,simulando um programa de telejornalismo com a temática "Direitos Humanos" em referência a palestra que receberam durante o evento da escola: "Semana da Educação para a Vida da Escola Serra da Moeda".

Tal escolha evidenciou outro exemplo de coincidência com as ideias de Freire de que todo indivíduo em qualquer nível de conhecimento busca instrumentalizar sua linguagem para comunicar-se. "E a comunicação, longe de se definir como a transmissão de uma mensagem ou um saber, é uma ação, um fazer. No ato de comunicação, o homem faz palavras, figuras, comparações, para contar o que ele pensa a seus semelhantes". [SODRE, 2012 p. 151].

E neste contexto, os alunos buscam apresentar a realidade em que vivem com o uso das tecnologias que agora estão disponíveis.

Com uma câmera de vídeo dentro da sala de aula ou da escola, os alunos, ao criarem seus próprios produtos audiovisuais, tendem a repetir os modelos massificados que estão acostumados a ver diariamente nas telas da televisão e, em menor escala, do cinema [COUTINHO, 2005, p. 19].

Para o desenvolvimento do produto digital, no caso o vídeo, após pesquisa junto com os alunos do IFTM foram escolhidos com referências metodológicas o GUIA VÍDEO NA ESCOLA (2016) do Instituto Recriar. eem TV ESCOLA O CANAL DA EDUCAÇÃO (2016). Em ambos os casos as propostas são orientadas para a) Democratizar o Acesso aos Instrumentos (liberdade), b) Interesse Coletivo, c) Prática da Cidadania, e d) Processos de Produção Colaborativos.

Neste contexto os alunos participaram de todas as atividades do processo, escolheram a temática de interesse coletivo voltado para prática de cidadania,escreveram o roteiro de forma colaborativa (com auxílio de um professor da escola), montaram o cenário para as filmagens, atuaram tanto como personagens do vídeo como também na parte técnica alternado-se no papel de camera man, fotografia, experimentando a liberdade de acesso aos instrumentos tecnológicos utilizados. 
V Congresso Brasileiro de Informática na Educação (CBIE 2016)

Anais dos Workshops do V Congresso Brasileiro de Informática na Educação (CBIE 2016)

Com tal experiência os alunos vivenciaram uma realidade diferente saindo da rotina do confinamento na sala de aula, saboreando a liberdade de se expressarem e explorar novas possibilidades de aprendizado.

Já para os alunos do curso Técnico em Informática do IFTM, aliar a área de Informática com as atividades rurais, além de incentivar o uso das Tecnologias de Informação e Comunicação (TICs), propicia oportunidades de compartilhar do conhecimento técnico das linguagens utilizadas nos sistemas comunicacionais, manejo da informação e dos dispositivos tecnológicos.

Assim, aprendem que o uso da tecnologia não se restringe em dominar hardware e software, ou seja, simplesmente a técnica pela técnica, pois de acordo com Bazzo et al. (2003) só isso é pouco, na educação tecnológica um profissional da área técnica também deve ter a consciência de seu papel, de seus compromissos e responsabilidades perante a coletividade de que participa, promover mudanças de atitudes e concepções criando ambientes de interação interpessoal e desenvolver habilidades sociais.

Essa experiência representa um salto qualitativo à sua formação que terá algo mais, o desenvolvimento de competências como: flexibilidade, trabalho em equipe, aspectos humanísticos, etc, o que o colocará em destaque no mercado de trabalho.

\section{Caminhos da colheita: conclusões e considerações finais}

As dificuldades e conquistas foram de grande aprendizado, mesmo que o material produzido não represente bons parâmetros de qualidade técnica, pois, o mais importante foi o processo em si, principalmente porque essas crianças e jovens têm importante papel na transmissão desses conhecimentos às suas famílias podendo até melhorar os recursos internos das propriedades rurais.

Além disso, educar não é apenas transmitir conhecimentos. A ideia da educação tecnológica é utilizar as TIC's para estimular o aluno a adquirir novos conhecimentos utilizando como apoio os dispositivos móveis, não somente no ambiente escolar como também no seu cotidiano. E esta realidade se aplicanão só para áreas urbanas quanto para comunidades rurais.

Algumas limitações estruturais foram encontradas, como o pouco espaço físico do laboratório de informática. O projeto, apesar de contar com apoio irrestrito da 
V Congresso Brasileiro de Informática na Educação (CBIE 2016)

Anais dos Workshops do V Congresso Brasileiro de Informática na Educação (CBIE 2016)

direção da escola, de início percebeu-se uma fraca interação dos demais professores durante as atividades. Uma melhor demonstração dos benefícios e resultados do projeto na comunidade escolar poderia melhorar o envolvimento dos professores facilitando uma abordagem multidisciplinar.

Com o projeto, percebemos que para uma verdadeira inclusão digital e consequentemente sócio-educacional, não basta disponibilizar recursos e dispositivos tecnológicos, pois muitos já o possuem mesmo vivendo em comunidades rurais, também se mostra importante estimular experiências comunicativas e o exercício da opinião e a interatividade entre aluno e professor.

Além disso, a partir do momento em que damos voz ao aluno, permitindo esse exercício de opinião com liberdade e responsabilidade, ele assume o papel de corresponsável pela sua formação, desenvolvendo, assim, práticas de autonomia.

A escola hoje de um modo geral se distancia do aluno por questões bem mais complexas do que estrutura tecnológica, é imperativo atenção ao despreparo do professor e melhores condições de trabalho para que estes possam fazer uso esperado das inovações tecnológicas.

Essa experiência nos possibilitou grande aprendizado no entendimento de que educação, comunicação e tecnologia andam juntas, sendo algo mais do que simplesmente lidar bem com teorias educacionais ou ferramentas computacionais, mas também a capacidade de construir o conhecimento baseado num processo contínuo de ressignificação do Aprender e Ensinar.

\section{Referências}

ALMEIDA, Maria Elizabeth Bianconcini de. Tecnologia na Escola: Criação de Redes de Conhecimentos. In: ALMEIDA, M. E. B.; MORAN, J. M. Integração das Tecnologias na Educação. Brasilia: SEED-MEC, 2005, p. 70-73.

APARICI, Roberto. Introdução: a educomunicação para além do 2.0. In: APARICI, Roberto (org.). Educomunicação: para além do 2.0.São Paulo: Paulinas, 2014, pp. $29-42$.

BAZZO, Walter Antonio; DO VALE PEREIRA, Luiz Teixeira; VON LINSINGEN, Irlan. Educação Tecnológica no contexto da Inovação Social. 2003. Disponível em: <http://www.abenge.org.br/CobengeAnteriores/2003/artigos/EDS593.pdf>. Acesso em: 27/05/2016. 
V Congresso Brasileiro de Informática na Educação (CBIE 2016)

Anais dos Workshops do V Congresso Brasileiro de Informática na Educação (CBIE 2016)

BRASIL. Lei $\mathbf{N}^{\circ}$ 9.394, de 20 de Dezembro de 1996. Estabelece as Diretrizes e Bases da Educação Nacional. 1996. Disponível em: http://www.planalto.gov.br/ccivil_03/leis/L9394.htm. Acesso em: 10/12/2011.

CENSO ESCOLAR 2014. Disponível em: < http://portal.inep.gov.br/basica-censo>. Acesso em: 21/05/2016.

COUTINHO, Laura Maria. Aprender com o Vídeo e a Câmera: Para Além das Câmeras, as Ideias. In: ALMEIDA, M. E. B.; MORAN, J. M. Integração das Tecnologias na Educação. Brasilia: SEED-MEC, 2005, p. 18-21.

FREIRE, Paulo. Pedagogia da autonomia. São Paulo: Paz e Terra, 2000.

GUIA VÍDEO NA ESCOLA - Instituto Recriar. Disponível em: <www.institutocriar.org/arquivos/guia_ilustrado_videocriar.pdf> acesso em: 29.abr.2016.

ROSA, Sanny S. da.Construtivismo e mudança.2 ed. São Paulo: Cortez, 1994.

SOARES, Ismar de Oliveira. Educomunicação, o conceito, o profissional, a aplicação. São Paulo, Paulinas, 2011.

Gestão Educomunicativa e educação: caminhos da educomunicação. Comunicação \& Educação, São Paulo, n 23, jan/abril 2002

SODRE, Muniz. Reinventando a educação: diversidade, descolonização e redes.Petrópolis, RJ:Vozes 2012.

TV ESCOLA O CANAL DA EDUCAÇÃO: Oficina TV Escola de Produção de vídeos. Disponível em: <http://curtahistorias.mec.gov.br/images/pdf/dicas _producao_videos.pdf>. Acesso em: 29.abr.2016. 